\title{
Influence of soft-start curing protocol in the degree of conversion of a nanohybrid resin composite
}

Heloisa Amorim Periotto ${ }^{a}$, Ana Daielly da Silva ${ }^{a}$, Isabella Saraiva Leão de Resende ${ }^{b}$, Sérgio Lima Santiago ${ }^{c}$, Jiovanne Rabelo Neria,b

\begin{abstract}
OBJECTIVE: To analyze the influence of the soft-start curing protocol in the degree of conversion of a nanohybrid composite.

METHODS: Ten specimens were prepared from the polymerization of the composite resin Llis using two protocols: conventional $\left(1000 \mathrm{~mW} / \mathrm{cm}^{2}\right.$ for 20 seconds) or gradual $\left(250 \mathrm{~mW} / \mathrm{cm}^{2}\right.$ for 20 seconds $+1000 \mathrm{~mW} / \mathrm{cm}^{2}$ for 15 seconds). Then, analyzes were performed using a spectrophotometer and data were subjected to Two-way ANOVA and Holm-Sidak test. The significance level was $5 \%$

RESULTS: There was no statistical difference between the average resin conversion degree of composite values in the base area and top for both curing protocols $(p>0.05)$.

CONCLUSION: Therefore, the use of soft-start curing protocol did not interfere in the degree of conversion of a nanohybrid composite.
\end{abstract}

Keywords: composite resins; polymerization; physical properties.

\section{Influência do protocolo de fotoativação gradual no grau de conversão de uma resina composta nanohíbrida}

\section{RESUMO}

OBJETIVO: Analisar a influência do protocolo de fotoativação gradual no grau de conversão de uma resina composta nanohíbrida.

METODOLOGIA: Dez espécimes foram confeccionados a partir da polimerização da resina composta Llis, utilizando os seguintes protocolos: convencional $\left(1000 \mathrm{~mW} / \mathrm{cm}^{2}\right.$, durante 20 segundos) ou gradual $(250 \mathrm{~mW} /$ $\mathrm{cm}^{2}$ durante 20 segundos $+1000 \mathrm{~mW} / \mathrm{cm}^{2}$ durante 15 segundos). Posteriormente, foram realizadas análises com espectrofotômetro e os dados foram submetidos à análise de variância a dois critérios e o teste de Holm-Sidak. O nível de significância adotado foi $5 \%$

RESULTADOS: Não houve diferença estatística entre a média dos valores de grau de conversão da resina composta na superfície de topo e de base, para ambos os protocolos de fotoativação $(p>0,05)$.

CONCLUSÃO: o uso do protocolo de fotoativação gradual não interferiu no grau de conversão de uma resina composta nanohíbrida.

Palavras-chave: resinas compostas; polimerização; propriedades físicas

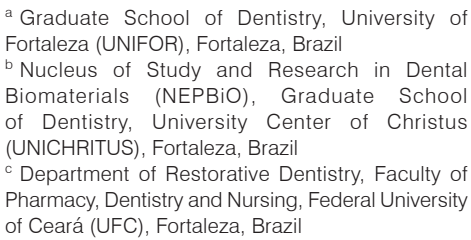

Graduate School of Dentistry, University of Fortaleza (UNIFOR), Fortaleza, Brazil

Nucleus of Study and Research in Dental Biomaterials (NEPBiO), Graduate School of Dentistry, University Center of Christus (UNICHRITUS), Fortaleza, Brazil

${ }^{c}$ Department of Restorative Dentistry, Faculty of Pharmacy, Dentistry and Nursing, Federal University of Ceará (UFC), Fortaleza, Brazil 


\section{INTRODUCTION}

The clinical performance of composite resin restorations has improved significantly in the last decades [1]. However, the occurrence of enamel and dentin cracks, cusp fractures, postoperative sensitivity and formation of gaps between the restoration and the tooth continue to be problems frequently observed in dental practice [2]. Many of these setbacks are related to the polymerization contraction of the composite resins and the stress generated at the tooth/restoration interface [3].

The polymerization reaction begins with the interaction between photons of visible light, at a wavelength between 400 and $500 \mathrm{~nm}$, and the initiators, producing extremely reactive free radicals [4]. Free radicals, in turn, promote the breakdown of the unsaturated carbon bonds $(\mathrm{C}=\mathrm{C})$, aliphatic $(1636 \mathrm{~nm})$ and aromatic $(1608 \mathrm{~nm})$ groups, and the dimethacrylate monomers, initiating a chain reaction [4]. A high degree of conversion of resinous monomers into polymers is fundamental for the composite resins to have satisfactory physical properties [5].

On the other hand, the process of forming the polymer chain of the composite resins leads to the approximation of the monomers, and reduces the intermolecular distance of approximately $4 \AA$ to $1.5 \AA$. Thus, the polymerization will lead to a significant volumetric reduction, which can vary between 2 and 4\% [6]. Such volumetric shrinkage, when occurring in the pre-gel phase (fluid composite resin), can be dissipated through the flow of the molecules of the material, allowing the stress relief [7]. However, when the gel-point is reached (passage from the fluid state to the viscous state), a significant increase occurs in the amount of crosslinking and in the modulus of elasticity of the material, resulting in the transmission of stresses to the dental structure [8]. The polymerization shrinkage stress can damage the marginal sealing of adhesive restorations, form gaps and promote cusp displacement $[3,9]$.

An alternative for reducing the polymerization shrinkage stress is the use of gradual curing protocol, also known as soft start [10]. In this protocol, a low power density is applied during the first phase of the polymerization period and a higher power density is used at the end of the irradiation [10]. This method of photoactivation allows the pre-gel phase to be prolonged, resulting in a greater relief of tensions generated during the polymerization shrinkage [11]. Studies have shown that the soft-startcuring protocol gives the composite resins satisfactory mechanical characteristics, similar to those obtained with the conventional protocol $[12,13]$.

The degree of conversion of the composite resins is influenced by several factors, among them the composition of the material [14]. Nanohybrid composite resins were marketed in order to be used on anterior and posterior teeth due totheir excellent initial polishing, gloss maintenance over time, and satisfactory mechanical properties [15]. These materials have inorganic particles of nanometric size $(0.02 \mu \mathrm{m})$ combined with particles of conventional size $(1 \mu \mathrm{m})$ [15]. Although composite nanohybrid resins are widely used, there are few studies that evaluate the use of the soft-startcuring protocol associated with this type of composite resin.

The aim of this study was to analyze the influence of the soft-start curing protocol on the degree of conversion of a nanohybrid composite resin. The null hypothesis tested was that there will be no significant difference in the degree of conversion of a nanohybrid composite resin independent of the curing protocol used.

\section{METHODS}

Ten specimens were performed with a nanohybrid composite resin - Llis $^{\circledR}$; FGM, Joinville, SC, Brazil (Table 1) using a metal matrix with a hole in the center with dimensions of $5 \mathrm{~mm}$ in diameter $\times 2 \mathrm{~mm}$ in height.

Each specimen was obtained from the insertion of a single increment of the composite resin in the center of the matrix, with the aid of a SuprafillDuflex spatula (SS White, Rio de Janeiro, RJ, Brazil). Subsequently, the composite resin increment was accommodated with a Hollenback \#5 metal condenser (Golgran, Sao Caetano do Sul, SP, Brazil), and covered with a polyester matrix and a glass cover, which was manually pressed by 60 seconds, promoting extravasation of excess material.

After removal of the glass cover, the specimens were photoactivated through the polyester tape by using a light curing unit (Poly Wireless; Kavo ${ }^{\circledR}$, Joinvile, SC, Brazil) following two curing protocols (Table 2).

Table 1. Composition of the composite resin

\begin{tabular}{ll}
\hline Composite resin & Composition \\
Composite resin Llis ${ }^{\circledR}$ & Bis-GMA monomers, Bis EMA, \\
(color dA3) & TEGDMA, camphorquinone, \\
& co-initiators, silane. Micronized \\
& barium-aluminosilicate glass, \\
& pigments and nanometric silica. \\
\hline
\end{tabular}

Bis-GMA: Bis-PhenolAdi-Glycidyl Methacrylate; Bis EMA: Bis-PhenolAdi-Glycidy Methacrylatoethoxylate; TEGDMA: Triethyleneglycoldimethacrylate.

Table 2. Description and energy density of the curing protocols.

\begin{tabular}{lcc}
\hline Curing protocol & Description & Energy density \\
\hline Conventional $(n=5)$ & $1000 \mathrm{mWcm}^{2}$ for $20 \mathrm{~s}$ & $20 \mathrm{~J} / \mathrm{cm}^{2}$ \\
Soft-start $(n=5)$ & $250 \mathrm{~mW} / \mathrm{cm}^{2}$ for $20 \mathrm{~s}+$ & $20 \mathrm{~J} / \mathrm{cm}^{2}$ \\
& $1000 \mathrm{~mW} / \mathrm{cm}^{2}$ for $15 \mathrm{~s}$ & \\
\hline
\end{tabular}

Immediately after photoactivation, the top and bottom surfaces of the specimens were identified and stored individually in amber vials at $37^{\circ} \mathrm{C}$ for 24 hours. To determine the degree of conversion, analyseswere made on top $(0 \mathrm{~mm})$ and bottom $(2 \mathrm{~mm})$ surfaces of each specimen by a Raman micro spectrometer (Xplora; Horiba Scientifc, Kyota, Japan). The spectrum was excited from the use of a laser with wavelength at $532 \mathrm{~nm}$ through an 
objective (100 X). The spectrum was obtained, according to the following conditions: irradiation time: $60 \mathrm{~s}$; number of accumulations: 10 and grade: 1200 lines $/ \mathrm{mm}$. The degree of conversion was calculated based on the reduction of the peak intensity corresponding to the $\mathrm{C}=\mathrm{C}$ methacrylate groups at $1,636 \mathrm{~cm}-1$ and $1,608 \mathrm{~cm}-1$ polymerized $(\mathrm{P})$ compared to the unpolymerized (U) specimen, according to the following equation:

$$
\text { Degree of conversion }=\left(1-\frac{P}{U}\right) \times 100
$$

From the data obtained, Shapiro-Wilk test was applied. Subsequently, Two-way ANOVA (curing protocol and surface area) and Holm-Sidak test for post-roc comparisons were applied. Statistical procedures were performed with Sigmastat 3.5 software for Windows (Systat Software Inc., San Jose, CA, USA) and in all situations, the level of significance was $5 \%$.

\section{RESULTS}

The degree of conversion values are shown in Table 3. The results were not influenced by the curing protocol $(\mathrm{p}=0.921, \mathrm{~F}=0.0103)$ and by the surface of the composite resin $(p=0.242, F=1.477)$. The interactions were not statistically significant $(\mathrm{p}=0.550, \mathrm{~F}=0.373)$.

There was no statistically significant difference between the degree of conversion values to the bottom and top surface for both curing protocols $(\mathrm{p}>0.05)$. In each surface (top or bottom), no statistically significant difference was observed between the degree of conversion values obtained from each curing protocol $(\mathrm{p}>0.05)$.

Table 3. Mean of the degree of conversion (\%) and standard deviation, between the surfaces, according to the curing protocol.

\begin{tabular}{lcc}
\hline \multirow{2}{*}{ Curing protocols } & \multicolumn{2}{c}{ Surfaces } \\
\cline { 2 - 3 } & Top & Bottom \\
Conventional $(n=5)$ & $81,2 \pm 4,0^{\mathrm{A}, \mathrm{a}}$ & $77,3 \pm 4,0^{\mathrm{A}, \mathrm{a}}$ \\
Soft-start $(n=5)$ & $80,1 \pm 2,4^{\mathrm{A}, \mathrm{a}}$ & $78,8 \pm 7,4^{\mathrm{A}, \mathrm{a}}$ \\
\hline
\end{tabular}

Notes: Similar capital letters indicate no significant difference in the columns; simila lowercase letters indicate no significant difference on the lines.

\section{DISCUSSION}

The degree of conversion of a composite resin corresponds to the percentage of double carbon bonds converted into single bonds to form a polymer chain [16]. This percentage is related to the mechanical properties of the composite resin, where a high degree of conversion is fundamental for its satisfactory clinical performance [17].

Different tests can be used to evaluate the degree of conversion of resin monomers, such as infrared Fourier transform spectroscopy [18], Raman spectroscopy [19,20], and microhardness tests [21]. In the present study, the direct method of evaluating the degree of conversion of the composite resins using Raman spectroscopy was used. Raman spectroscopy quantifies the degree of conversion during polymerization by comparing non-polymerized residual methacrylate vibration bands [9].

The proper polymerization of the composite resins is directly related to their degree of conversion. In the attempt to promote high conversion of monomers into polymers associated with low shrinkage stress, different curing protocols were developed [22]. In the conventional curing protocol, a highpower light is applied, in a constant mode, which should result in higher degree of conversion values [23]. However, some studies have shown that the use of this protocol does not result in a greater degree of conversion when compared to other protocols $[13,24]$. These data corroborate with the findings of the present study (Table 3).

On the other hand, the possibility of negative influence of the high light intensity on the development and relaxation of the shrinkage stress should be considered. The instantaneous passage from a less viscous (pre-gel) state to a rigid (postgel) state, rapidly increases the modulus of elasticity and reduces the possibility of relief from the polymerization shrinkage [25]. In attempt to reduce this issue, the softstartcuring protocol was developed. This protocol uses low initial light intensity, forming a smaller number of free radicals, which limits the amount of methacrylate monomers groups converted into polymers [11]. This way, the polymerization reaction proceeds more slowly, allowing stress relief through the flow of the molecules (pre-gel phase). When the composite resin reaches the gel point, the maximum flow will occur, and then light with high intensity will be applied to complement the polymerization reaction [11].

When polymerization is carried out with low light intensity, the composite resin can be sub-polymerized, resulting in a low degree of conversion of monomers into polymers, with consequent damage to the properties of the material [21]. However, Emami and Solderholm [24] concluded that different protocols using equivalent energy density give similar degree of convertion values, regardless of the low initial energy intensity applied. These findings corroborate with the results of the present study. This way, the null hypothesis failed to be rejected.

The methodology used to evaluate the degree of conversion of the composite resins through Raman spectroscopy does not provide data on the shrinkage stress, being a limitation of the present study. Therefore, new studies should be developed to evaluate the influence of soft-startcuring protocol on the reduction of shrinkage stress of composite resins.

\section{CONCLUSION}

According to the applied methodology, it was verified that the use of soft-startcuring protocol did not interfere in the degree of conversion of a composite nanohybrid resin. 


\section{ACKNOWLEDGMENTS}

This work was funded thanks to grants FUNCAP BMD-0008-01278. $01.01 / 17$

\section{REFERENCES}

1. Pallesen $U$, van Dijken JW. A randomized controlled 30 years follow up of three conventional resin composites in Class II restorations. Dent Mater 2015;31(10):1232-44. https://doi.org/10.1016/j.dental.2015.08.146

2. Fronza BM, Rueggeberg FA, Braga RR, Mogilevych B, Soares LE, Martin AA, Ambrosano G, Giannini M. Monomer conversion, microhardness, internal marginal adaptation, and shrinkage stress of bulk-fill resin composites. Dent Mater 2015; 31(12):1542-51. https://doi.org/10.1016/j. dental.2015.10.001

3. Ferracane JL, HiltonTJ. Polymerization stress is it clinically meaningful? Dent Mater 2016;32(1):1-10. https://doi.org/10.1016/j.dental.2015.06.020

4. Selig D, Haenel T, Hausnerová B, Moeginger B, Labrie D, Sullivan B, Price $\mathrm{R} B$. Examining exposure reciprocity in a resin based composite using high irradiance levels and real-time degree of conversion values. Dent Mater 2015;31(5):583-93. https://doi.org/10.1016/j.dental.2015.02.010

5. Cekic-Nagas I, Egilmez F, Ergun G. The effect of irradiation distance on microhardness of resin composites cured with different light curing units. Eur J Dent 2010;4(4):440-6.

6. Ausiello P, Apicella A, Davidson CL. Effect of adhesive layer properties on stress distribution in composite restorations - a 3D finite element analysis. Dent Mater. 2002;95:295-303. https://doi.org/10.1016/S01095641(01)00042-2

7. Lim BS, Ferracane JL, Sakaguchi RL, Conson JR. Reduction of polymerization contraction stress for dental composites by two-step light activation. Dent Mater 2002;18(6):436-44. https://doi.org/10.1016/S01095641(01)00066-5

8. Sakaguchi RL, Peters MCRB, Nelson SR, Douglas WH, Poort HW. Effects of polymerization contraction in composite restorations. J Dent. 1992; 20(3):178-182. https://doi.org/10.1016/0300-5712(92)90133-W

9. Verluis A, Tantbirojn D. Theoretical considerations of contraction stress. Compend Contin Educ Dent 1999;1(25):24-32.

10. Dewaele M, Asmussen E, Peutzfeldt A, Munksgaard EC, Benetti AR, Finné G, Leloup G, Devaux J. Influence of curing protocol on selected properties of light-curing polymers: Degree of conversion, volume contraction, elastic modulus, and glass transition temperature. Dent Mater. 2009;25(12): 1576-84. https://doi.org/10.1016/j.dental.2009.08.001

11. Chan DC, Browning WD, Frazier KB, Brackett MG.Clinical evaluation of the soft-start (pulse-delay) polymerization technique in Class I and II composite restorations. Oper Dent 2008;33(3):265-71. https://doi. org/10.2341/07-120

12. Mehl A, Hickel R, Kunzelmann KH. Physical properties and gap formation of light-cured composites with and without "soft-start polymerization".
J Dent 1997:25(3-4):321-30. https://doi.org/10.1016/S0300-5712(96) 00044-9

13. Emami N, Soderholm KJM, Berglund LA. Effect of light power density variations on bulk curing of dental composites. J Dent 2003;31(3):189-96.

14. Aguiar FHB, Braceiro ALT, Ambrosano GMB, Lovadino JR. Hardness and diametral tensile strength of a hybrid composite resin polymerized with different modes and immersed in ethanol or distilled water media. Dent Mater 2005;21(12):1098-103. https://doi.org/10.1016/j.dental.2004.11.010

15. Senawongse $P$, Pongprueksa $P$. Surface roughness of nanofill and nanohybrid resin composites after polishing and brushing. J Esthet Restor Dent 2007;19(5):265-73. https://doi.org/10.1111/j.17088240.2007.00116.x

16. Ferracane $\mathrm{JL}$, Matsumoto $\mathrm{H}$, Okabe T. Time-dependent deformation of composite resins - compositional considerations. J Dent Res 1985;64(11): 1332-1336. https://doi.org/10.1177/00220345850640111701

17. Caughman WF, Caughman GB, Shiflett RA, Rueggeberg F, Schuster GS. Correlation of cytotoxicity, filler loading and curing time of dental composites. Biomaterials 1991;12(8):737-40. https://doi.org/10. 1016/0142-9612(91)90022-3

18. Rueggeberg FA, Craig RG. Correlation of parameters used to stimate monomer conversion in a light-cured composite. J Dent Res 1988;67(6): 932-7. https://doi.org/10.1177/00220345880670060801

19. Par M, Lapas-Barisic M, Gamulin O, Panduric V, Spanovic N, Tarle Z.Long Term Degree of Conversion of two Bulk-Fill Composites. Acta stomatol Croa 2016;50(4):292-300. https://doi.org/10.15644/asc50/4/2

20. Al-Zain AO, Eckert GJ, Lukic H, Megremis SJ, Platt JA. Degree of conversion and cross-link density within a resin-matrix composite. J Biomed Mater Res Part B 2017;8(00):1-9.

21. Resende ISL, Bonfim, AGM, Passos VF, Santiago SL. Avaliação indireta do grau de conversão de resina composta utilizando doisprotocolos de fotoativação. Rev abo Nac 2011;19(2):96-100.

22. Ferracane $\mathrm{JL}$. Developing a more complete underestanding of stresses produced in dental composites during polimeryzation. Dent Mater 2005: 21:36-42. https://doi.org/10.1016/j.dental.2004.10.004

23. Obici AC, Sinhoreti MAC, Sobrinho LC, Goes MF, Consani S. Evaluation of depth of cure and knoop hardness in a dental composite photo-activated using different methods. Braz Dent J 2004; 15(3):199-203. https://doi. org/10.1590/S0103-64402004000300007

24. Emami N, Soderholm KJM. How light irradiance and curing time affect monomer conversion in light-cured resin composites. EurJOral Sci 2003; 111(6):536-42. https://doi.org/10.1111/j.0909-8836.2003.00082.x

25. Franco EB, Lopes LG. Conceitos atuais na polimerização de sistemas restauradores resinosos. Biodonto 2003;1(2):13-55. 